\title{
CHRONIC STRESS MODULATES THE VIRUS-SPECIFIC IMMUNE RESPONSE TO LATENT HERPES SIMPLEX VIRUS TYPE $1^{1,2}$
}

\author{
Ronald Glaser, Ph.D. and Janice K. Kiecolt-Glaser, Ph.D. \\ Institute for Behavioral Medicine Research \\ The Ohio State University College of Medicine
}

\begin{abstract}
We compared 71 family caregivers of dementia sufferers and 58 control subjects on three different immune measures relevant to latent herpes simplex virus Type 1 (HSV-1) infection: neutralizing antibody titers, antibody titers to a total viral antigen, and a proliferative memory T-cell response. Caregivers had significantly higher antibody titers to the total viral antigen and a poorer HSV-1 specific $T$-cell response than controls, but no significant difference in neutralizing antibody titers between groups was observed. These data provide additional evidence that psychological stress can modulate a virus-specific immune response associated with caregiving.
\end{abstract}

\section{(Ann Behav Med 1997, 19(2):78-82)}

\section{INTRODUCTION}

A number of studies have shown significant differences between family caregivers of Alzheimer's disease (AD) patients and non-caregivers on different components of the cellular immune response. These convergent data suggest that caregivers have poorer immune function than their well-matched community counterparts (1-3). For example, caregivers' peripheral blood leukocytes (PBLs) showed reduced proliferative responses to two T-cell mitogens compared to controls (2); in addition, caregivers' higher antibody titers to latent Epstein-Barr Virus (EBV), a human herpesvirus, suggested some loss of control over replication of latent $\mathrm{EBV}$, probably mediated by a down-regulation of the cellular immune response (4). McCann (3) showed that delayed hypersensitivity skin testing was markedly poorer in 34 spousal caregivers than 33 comparable non-caregivers. In fact, compared to normal age and gender standards, $50 \%$ of the caregivers were totally or relatively anergic, compared to only $12 \%$ of non-caregiver controls.

Irwin et al. (5) investigated the effects of AD caregiving stress on sympathetic nervous system activity, natural killer (NK) cell cytotoxicity, and plasma levels of neuropeptide Y (NPY). NPY levels were significantly elevated in older spousal caregivers compared to older controls, and NPY was negatively correlated

\footnotetext{
${ }^{1}$ Preparation of this manuscript was supported in part by grants R37 MH42096, R01 MH50538, and by Ohio State University Comprehensive Cancer Center core grant CA 16058

2 We thank Leigh Ann Kutz, Elizabeth Byrnes, Bryon Laskowski, and Jessica Candelora for excellent technical assistance. We also thank Dr. John Sheridan for comments on the manuscript. We also thank the Central Ohio Chapters of the Alzheimer's Association and the Parkinson's Disease Association for their support.
}

Reprint Address: R. Glaser, Ph.D., 2175 Graves, 333 West Tenth Avenue, Columbus, $\mathrm{OH} 43210$.

(c) 1997 by The Society of Behavioral Medicine. with NK cell activity among caregivers. Relatedly, caregivers' NK cells showed a poorer response to the stimulatory effects of recombinant interferon-gamma and recombinant interleukin-2 (IL-2) than NK cells from controls $(1,6)$. Consistent with these immunological differences, caregivers reported significantly more days ill than controls (primarily upper respiratory tract infections) in accord with data collected independently from their physicians (2). Other research has highlighted differences in cardiovascular functioning as well $(7-10)$.

In earlier work, we found that academic examinations, a much milder and more transient stressor than caregiving, were associated with modulation of the expression of the latent herpesviruses, EBV, and Herpes Simplex Virus Type 1 (HSV-1). During examinations, students had higher antibody titers to these latent herpesviruses than during lower-stress periods, as well as a poorer virus-specific memory T-cell response to EBV (11-14). An increase in antibody titers to a latent herpesvirus reflects the memory immune response to an increase in the production of viral antigens after reactivation of the virus; thus, higher titers to a latent herpesvirus suggest that the cellular immune response is less competent in controlling herpesvirus latency. No significant changes in antibody titers to poliovirus type-2 (a non-latent virus) and no evidence for a primary infection with EBV were observed (11). Consistent with these data from medical students, we found higher antibody titers to latent $E B V$ in $A D$ family caregivers than well-matched controls $(2,15)$.

In the present study, we focused on the memory T-cell and humoral immune response (mernory) to latent HSV-1 to determine if the virus-specific immune response to HSV-1 was influenced by caregiving. HSV-1 has been associated with primary and recurrent infections of mucous membranes such as herpes labialis, genital infections, stomatitis, keratoconjunctivitis, and herpes simplex encephalitis (reviewed in 16). As in the case of other human herpesviruses, virus latency is established after primary infection. The virus is ubiquitous among the North American population, and more than $90 \%$ of individuals have antibody to HSV-1 by the fourth decade of life (17). Individuals who are HSV-1 IgG antibody positive are latently infected with the virus. Under certain conditions, particularly immune suppression, latent HSV-1 is reactivated. Friedman et al. (18) and Goldmeier and Johnson (19) have shown that psychological stress can reactivate oral and genital HSV-1. In this study, we sought to determine if caregiving stress altered immune responses to latent HSV-1 infection.

\section{METHOD}

Caregivers were recruited from three local dementia evaluation centers in area hospitals, neurologists' referrals, the city's Alzheimer's Disease Association support groups and monthly newsletter, and respite care programs. While the majority of the caregivers' impaired spouses or parents had a diagnosis of Alzheimer's disease $(N=45), 3$ were diagnosed as multi-infarct 
dementia, 18 as Parkinson's disease with progressive dementia, and 5 with Huntington's disease; comparisons of Alzheimer's disease caregivers with caregivers for other progressive dementias suggest that dementia caregiving produces similar adverse effects in family members (20).

About half of the caregivers were providing care for a spouse $(N=34)$, while the remainder were providing care for a parent. The average caregiver had been providing care for 7.66 years $(\mathrm{SEM}=4.56)$ and provided 4.86 hours of care per day (5.04).

Control subjects in our longitudinal study were recruited through newspaper advertisements, church groups, notices posted in senior citizen centers, and referrals from other participants; potential control subjects who reported any caregiving activities were excluded. Caregivers or controls with immunologicallyrelated health problems such as cancer or recent surgeries were excluded. The Ohio State University Biomedical Research Review Committee approved the project; all subjects gave written informed consent prior to participation.

\section{Subject Characteristics}

The 71 caregivers ( 58 women and $13 \mathrm{men}$ ) and 58 controls ( 45 women and 13 men) did not differ on age or family income, $F s<1$. Caregivers' mean age was $60.55(\mathrm{SEM}=1.52$ ) compared to 62.41 $(\mathrm{SEM}=1.98$ ) for controls, with a range from 35 to 84 . The modal subject reported an annual family income between $\$ 20,000$ and $\$ 30,000$ and had completed several years of college. The majority (92\%) were White. Among caregivers, $57(80.3 \%)$ were married, 8 $(11.3 \%)$ were separated or divorced, $2(2.8 \%)$ were widowed, and $4(5.6 \%)$ had never married; although most non-caregivers were married $(74 \%), 8(13.8 \%)$ were separated or divorced and 7 $(12.1 \%)$ were widowed. While the groups were not matched on marital status, the inclusion of more unmarried control subjects worked against confirmation of the experimental hypotheses, because intact marriages are associated with lower rates of morbidity and mortality as well as better immune function $(21,22)$.

The ten-item Perceived Stress Scale (PSS) (23) measures the degree to which individuals assess perceptions of daily life in the prior week as unpredictable, uncontrollable, and overloading, dimensions of particular interest in caregivers. Subjects rate each item from 0 (never) to 4 (very often). For our sample, coefficient alpha was .77.

\section{Status of the Dementia Patient}

The Blessed Dementia Scale (BDS) (24) was developed to measure negative changes in a demented person's abilities across daily living, self-care, and personality domains. Higher scores on this 22-item scale denote greater decrements in ability, with a potential range of 0 to 28 . BDS scores correlate with senile plaque count during postmortem histological examination (24). In addition, the BDS correlates with neuropsychological testing and can be used to differentiate degree of dementia (25).

The Memory and Behavior Problem Checklist (MBPC) (26) measures behavioral excesses and deficits in dementia patients and the caregiver's reaction to those problems. The 29 items include some of the problems most distressing to caregivers (e.g. the patient's inability to dress and feed himself/herself, incontinence, inability to communicate, hiding things, and inability to recognize familiar people). The scale provides three scores: a measure of the frequency of problem behaviors, a measure of associated caregiver distress, and a third score that combines frequency and reaction to produce a summary measure. The MBPC measures current symptoms and associated subjective caregiver distress, not impairment of the patient per se, as many behavior problems are most prevalent in the middle stages of dementia.

We collected health-related data to assess the possibility that caregiving-immunological relationships might simply reflect the contribution of other variables. Plasma albumin levels, recent weight loss, and body mass data provided information on the nutritional status of subjects. We asked subjects about recent sleep compared to their normal requirements, weight change in the last two weeks, medication use, alcohol use, smoking, exercise, and caffeine intake.

We used a modified version (27) of the Health Review (28) to collect data on cold sores. Subjects were given the interview in person during the annual interview, then called every three months. During Health Review interviews, we used a number of methods to ensure the most accurate and complete recall as described elsewhere (27).

\section{Immunological Studies}

Blood for all subjects was drawn between 8:00 a.m. and 10:00 a.m. to control for diurnal variation; this was important for the T-cell response study. Interviews followed blood draws. Caregivers and controls were evaluated in mixed groups across the year, so that we were always simultaneously collecting blood from both groups. For this series of experiments, we simply used sequential caregivers and controls from the annual data collection who were part of our longitudinal study.

\section{The Determination of Antibody Titers to HSV-1 by ELISA}

In order to determine antibody titers to HSV-1, an ELISA was performed using a total virus antigen preparation obtained from virus-infected Vero cells. The protein concentration of the virus stock was determined by a Bio-Rad Protein assay using routine procedures. We defined endpoint antibody titers as the optical density (OD) value of the highest dilution of a plasma sample which was greater than two standard deviations above the negative serum control value.

\section{HSV-1 Virus Neutralizing Antibody Titers}

In order to determine neutralizing antibody titers to HSV-1, monolayers of Vero cells were grown in 24-well plates. Two-fold dilutions of plasma prepared in phosphate buffered saline (PBS), starting at $1: 2$, were incubated with 100 tissue culture infectious doses (TCIDs) $/ \mathrm{ml} \mathrm{HSV-1}$ for one hour at $37^{\circ}$. HSV-1 positive and negative plasma controls along with a media + virus control $(100$ TCIDs) were included.

Diluted plasma/virus preparations and control preparations were added to the wells. The plates were incubated at $37^{\circ} \mathrm{C}$ in an atmosphere of $5 \% \mathrm{CO}_{2}$ for 48 hours. Virus neutralization titers were determined by the highest dilution of plasma able to completely block the development of virus-specific cytopathologic effect (CPE).

\section{Measurement of the HSV-1 Specific T-Cell Response by Cell Proliferation}

Peripheral blood leukocytes were obtained from each subject and prepared at a concentration of $1 \times 10^{6} \mathrm{cells} / \mathrm{ml}$ in RPMI 1640 medium supplemented with 5\% Fetal Bovine Serum (FBS). One hundred $\mu$ of the suspension was added to each of three wells in a 96-well plate. The HSV-1 antigen was prepared as described above. The initial protein concentration of the stock used for these experiments was $2.52 \mathrm{mg} / \mathrm{ml}$. The viral antigen was U.V. inactivated, diluted 1:3 and 1:27 in PBS, and used to measure HSV-1 


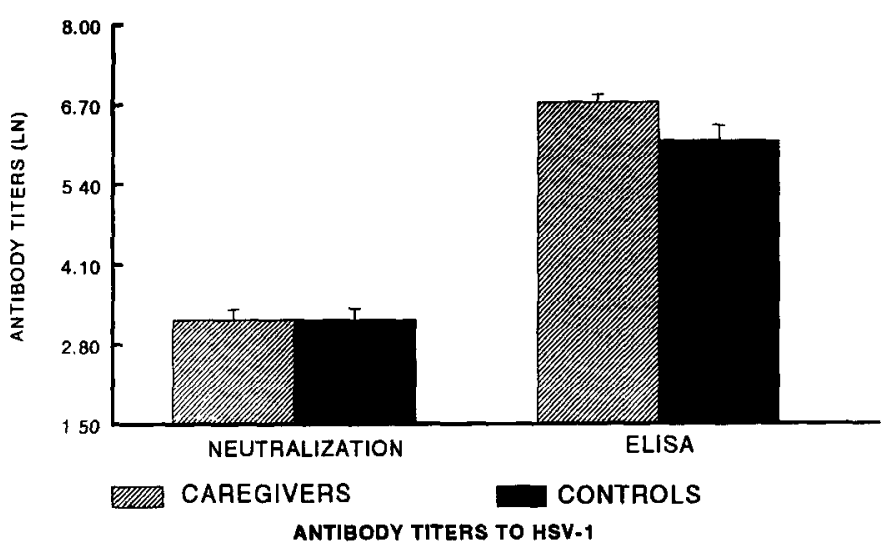

FIGURE 1: Means (SEM) for caregivers and controls for antibody titers to HSV-1 as measured by two methods, virus neutralization and ELISA. The data for virus neutralization only includes those subjects with measurable antibody.

specific memory T-cell proliferation. Wells containing PBLs in media alone were the controls. The cultures were incubated for 160 hours at $37^{\circ} \mathrm{C}$ then pulsed for 8 hours with tritiated thymidine (specific activity $0.1 \mathrm{mCi} / \mathrm{ml}$ ); radioactivity (cpm) as a measure of cell proliferation was determined using a Beckman LS7000 scintillation counter.

\section{Data Analyses}

We used univariate and multivariate analyses of variance (ANOVAs and MANOVAs) to assess differences between caregivers and controls and the interaction of these variables. Antibody and T-cell proliferation data were subjected to natural log transformations to normalize the distributions prior to analyses. Chi-square tests were used to analyze dichotomous data. All correlations reported are Pearson correlations.

Throughout our data, we found no significant gender differences. Thus, while gender was included as a variable in earlier analyses, sex differences will not be reported.

\section{RESULTS}

All subjects had measurable antibody (IgG) to the HSV-1 total virus antigen by ELISA. As expected, caregivers had significantly higher antibody titers than controls, $\mathrm{F}(1,127)=5.47, p<.03$ (Figure 1).

In contrast to the ELISA data, 34 subjects had no measurable neutralizing antibody to HSV-1 $(26.4 \%)$. Of these, 22 were caregivers (31\% of all caregivers) and 12 were controls $(20.7 \%)$, $\chi^{2}(1, N=129)=1.74$. Comparisons of neutralizing antibody titers between those caregivers and controls who had measurable neutralizing antibody showed no significant difference, $\mathrm{F}<1$.

We also examined subjects' recent cold sore history: 21 subjects $(16.3 \%)$ reported that they had experienced at least one cold sore during the previous twelve months. Fourteen of the 21 subjects were caregivers [i.e. $20 \%$ of caregivers had a cold sore compared to $12 \%$ of controls, $\left.\chi^{2}(1, N=129)=1.49\right]$. These differences, however, were not significant.

Examining these data in the context of the immunological data, only 2 of the 21 subjects who reported a cold sore within the last year had no detectable neutralizing antibody, $\chi^{2}(1, N=129)=$ $3.66, p=.05$. Importantly, among those subjects who had not experienced a cold sore within the last twelve months, $37 \%$ of the caregivers (21 out of 57) had no neutralizing antibody compared to

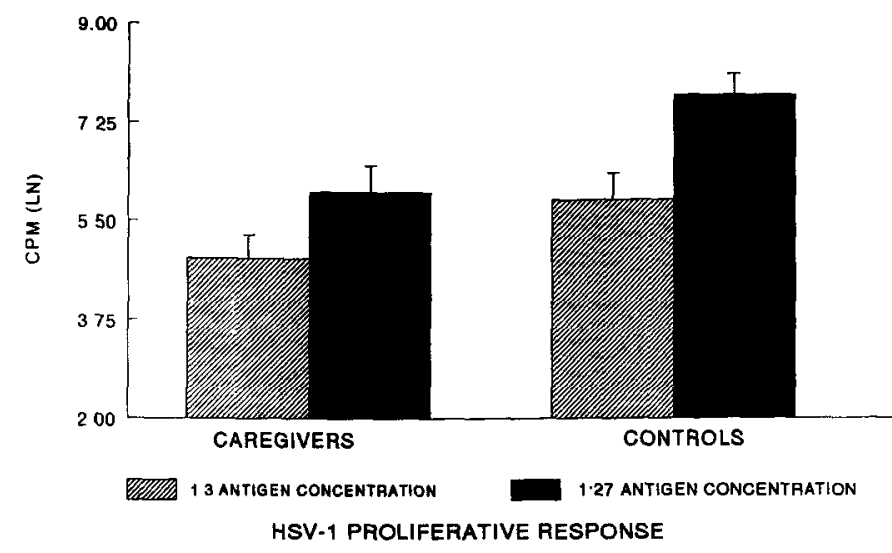

FIGURE 2: Means (SEM) proliferative memory T-cell responses to $\mathrm{HSV}-1$ for caregivers and controls.

$22 \%$ of controls (11 out of 51 ), a difference that approached significance, $\chi^{2}(1, N=129)=3.01, p<.08$.

The HSV-1 specific memory T-cell response, measured by incorporation of tritiated thymidine (cpm) to determine cell proliferation, was analyzed using a MANOVA with one withinsubjects variable (change across the two concentrations of antigen), as well as one between-subjects variable, group membership. The proliferative response to $\mathrm{HSV}-1$ was significantly poorer among caregivers than controls, $\mathrm{F}(1,127)=5.69, p<.02$ (Figure $2)$. The higher concentration of antigen produced a greater proliferative response, as expected, $\mathrm{F}(1,127)=19.59, p<.001$, with a non-significant interaction between group and concentration of antigen, $\mathrm{F}(1,127)=1.00$.

When data for the HSV-1 T-cell response were analyzed using a MANOVA with the same within-subjects variable (change across the two concentrations), as well as two between-subjects variables, group membership and presence/absence of neutralizing antibody to $\mathrm{HSV}-1$, the T-cell response to $\mathrm{HSV}-1$ was again significantly poorer among caregivers than controls, $\mathrm{F}(1,125)=6.83, p<.01$. In addition, subjects who had no neutralizing antibody also showed a poorer proliferative response to $\mathrm{HSV}-1, \mathrm{~F}(1,125)=34.93, p<$ .001 , without a significant interaction between the two grouping variables, $F(1,125)=3.14$. Thus, both caregiving and the absence of neutralizing antibody were associated with a poorer virusspecific proliferative response.

\section{Demographic and Health-Related Behaviors}

Subjects' age was not related to either the presence of neutralizing antibody, $F(1,127)=2.09$, or to the development of a cold sore in the prior year, $F(1,127)=1.96$. Caregivers did not show reliable differences from the controls on alcohol intake, recent weight change, frequency of vigorous physical exercise, or caffeine intake, Fs $<1$. The two groups did not differ in body mass or weight change within the last week, Fs $<1$. All subjects were within normal ranges on plasma albumin values.

As would be expected from our own and other studies, caregivers and controls did show reliable differences in sleep. Caregivers reported an average of 22.44 hours of sleep in the three days preceding the blood draw $(\mathrm{SEM}=0.37)$, compared to controls' 23.69 hours $(\mathrm{SEM}=\mathbf{0 . 2 3}), \mathrm{F}(1,123)=7.22, p<.01$. Nevertheless, correlations between sleep and immunological data were small ( -.01 to .13$)$, and none was significant. Thus, differences in health behaviors would not appear to be driving the immunological differences. 


\section{Psychological Stress and Caregiving}

Consistent with numerous studies on stress and depression associated with caregiving, caregivers reported significantly higher levels of stress on the ten-item PSS than non-caregivers, $F(1,121)=$ $18.28, p<.001$. Caregivers' mean score was $18.00(\mathrm{SEM}=0.83)$, compared to non-caregivers' mean of 12.97 (SEM = 0.79).

Caregiver variables including years of caregiving, hours per day of care, or scores on the Blessed Dementia Scale and the Memory and Behavior Problem Checklist did not show significant relationships to the absence of neutralizing antibody or the development of cold sores. Correlations between these caregiver variables and immunological data were not significant. There were no significant differences in perceived stress or on any of the immunological measures when we compared spouse and adult child caregivers.

\section{DISCUSSION}

In previous studies involving caregivers of dementia patients, we found evidence of the modulation of latent $\operatorname{EBV}(2,15)$. These studies were extended to determine if the virus-specific immune response to latent $\mathrm{HSV}-1$ infection was influenced by the stresses of caregiving with respect to three different markers related to the HSV-1 specific immune response: levels of neutralizing antibody, antibody titers to a total viral antigen preparation, and a memory proliferative T-cell response.

When a person is infected with HSV-1, antibodies are synthesized to virtually all viral proteins, resulting in a "pool" of antibodies to viral antigens. However, there are generally one or more viral glycoproteins which are important for producing an antibody that will neutralize virus infectivity (i.e., neutralizing antibody). To determine if the neutralizing antibody is present, cells are infected in vitro with HSV-1 treated with the serum or plasma; the presence of the neutralizing antibody is determined by the ability to block infection of the cells (reviewed in 16,29,30). It is the neutralizing antibody that is thought to be clinically relevant in protecting against reinfection.

Since most individuals are latently infected with HSV-1 by the time they reach their forties (17), we anticipated that virtually $100 \%$ of our subjects would have measurable $\operatorname{IgG}$ antibody to HSV-1, as determined by ELISA, which was the case. In addition, caregivers had significantly higher antibody titers to the total viral antigen by ELISA than controls. In contrast, $26.4 \%$ of subjects had no measurable neutralizing antibody to HSV-1, and neutralizing antibody titers did not differ between caregivers and controls. These data suggest that, as previously observed in similar subjects latently infected with EBV, caregiving stress has influenced the control over the steady state expression of the latent HSV-1 genome resulting in an increase in the expression of at least some viral proteins which over time has resulted in increases in IgG antibody titers; neutralizing antibody levels were not affected.

Data from a previous study with EBV may be pertinent for interpreting these results. Reactivation of latent $\mathrm{EBV}$ in medical students experiencing academic stress may be incomplete, and some viral proteins may not be expressed under certain circumstances, resulting in the production (or lack) of certain viral specific antibodies (13). It is possible that insufficient amounts of the major HSV-1 glycoprotein, gD (and other glycoproteins that induce neutralizing antibody) were not synthesized in the neutralizing antibody-negative subjects (31).

Stress is clearly associated with the modulation of herpesvirus infection, and some studies have demonstrated clinical consequences. For example, psychological stress has been linked to the development and severity of EBV-associated infectious mononucleosis (32). Animal studies have also demonstrated the impact of stress on the virus-specific primary and memory immune responses to HSV-1 in mice (33). Various stressors appear to affect the appearance, duration, and intensity of herpesvirus infections, presumably as a result of increased levels of "stress hormones" associated with the hypothalamic pituitary axis and the modulation of the virus-specific cellular immune response (34).

The reactivation of latent HSV-1 is generally not associated with significant clinical symptoms and occasionally associated with the common cold sore $(35,36)$. The differences in antibody patterns observed in the caregivers as compared to the control subjects were not associated with an increase in cold sores in this study; perhaps a study involving a larger group of subjects would show this relationship. However, the data continue to show that alterations in a virus-specific immune response are associated with caregiving and provide additional evidence that psychological stress is associated with poorer control of a latent herpesvirus.

As already discussed, we previously found that caregivers reported significantly more days ill than controls (2). We now provide additional evidence that caregiving stress has other important health implications. In a recent study, we found that healing of a 3.5 millimeter punch biopsy wound took $24 \%$ longer in caregivers than in controls, and PBLs from caregivers produced significantly less interleukin- 1 beta (IL-1 $\beta$ ) mRNA in response to lipopolysaccharide stimulation than did cells from non-caregivers. Stress-related defects in wound repair could have important clinical implications for both minor and major surgeries (37).

We also found that both the humoral and virus-specific cellular immune response to inoculation of an influenza virus vaccine was significantly down-regulated in caregivers as compared to control subjects (38). Caregivers were less likely to show a four-fold increase in antibody titers four weeks after vaccination; they had lower levels of in vitro stimulated IL-1 $\beta$; and their PBLs produced lower levels of interleukin-2 (IL-2) in response to vaccine (antigen) stimulation. Adults who show poorer responses to vaccines and other antigenic challenges also experience higher rates of clinical illness, including influenza virus infections $(39,40)$. Thus, these vaccine data suggest that caregivers are more vulnerable than their age-peers to influenza and, potentially, to other infectious agents (38-41).

Dementia caregiving is clearly associated with adverse mental health consequences (42). Data from studies showing such important health consequences as wound healing (37) and poor influenza vaccine responses (38) add weight to the contention that the chronic stress of caregiving can have adverse consequences for older adults' physical health as well.

\section{REFERENCES}

(1) Esterling B, Kiecolt-Glaser JK, Bodnar J, Glaser R: Chronic stress, social support, and persistent alterations in the natural killer cell response to cytokines in older adults. Health Psychology. 1994, 13:291-299.

(2) Kiecolt-Glaser JK, Dura JR, Speicher CE, Trask OJ, Glaser R: Spousal caregivers of dementia victims: Longitudinal changes in immunity and health. Psychosomatic Medicine. 1991, 53:353-362.

(3) McCann JJ: Effects of stress on spouse caregivers' psychological health and cellular immunity. Unpublished doctoral dissertation, Rush University College of Nursing, Chicago, IL, 1991.

(4) Glaser R, Kiecolt-Glaser JK: Stress-associated immune modulation and its implications for reactivation of latent herpesviruses. In Glaser R, Jones JF (eds), Herpesvirus Infections. New York: Marcel Dekker, Inc., 1994, 245-270. 
(5) Irwin $\mathrm{M}$, Brown $\mathrm{M}$, Patterson $\mathrm{T}$, et al: Neuropeptide $\mathrm{Y}$ and natural killer cell activity: Findings in depression and Alzheimer caregiver stress. FASEB Journal. 1991, 5:3100-3107.

(6) Esterling BA, Kiecolt-Glaser JK, Glaser R: Psychosocial modulation of cytokine-induced natural killer cell activity in older adults. Psychosomatic Medicine. 1996, 58:264-272.

(7) Uchino BN, Kiecolt-Glaser JK, Cacioppo JT: Age-related changes in cardiovascular response as a function of a chronic stressor and social support. Journal of Personality and Social Psychology. 1992, 63:839-846.

(8) Uchino BN, Kiecolt-Glaser JK, Cacioppo JT: Construals of preiliness relationship quality predict cardiovascular response in family caregivers of Alzheimer's disease victims. Psychology and Aging. 1994, 9:113-120.

(9) Vitaliano PP, Dougherty CM, Siegler IC: Biopsychosocial risks for cardiovascular disease in spouse caregivers of persons with Alzheimer's disease. In Abeles RP, Gift HC, Ory MG (eds), Aging and Quality of Life. New York: Springer, 1994.

(10) Vitaliano PP, Russo J, Niaura R: Plasma lipids and their relationships with psychosocial factors in older adults. Journals of Gerontology. 1995, 50B:18-24.

(11) Glaser R. Kiecolt-Glaser JK, Speicher CE, Holliday JE: Stress, loneliness, and changes in herpesvirus latency. Journal of Behavioral Medicine. 1985, 8:249-260.

(12) Glaser R, Rice J, Sheridan J, et al: Stress-related immune suppression: Health implications. Brain, Behavior and Immunity. 1987, $1: 7-20$.

(13) Glaser R, Pearson GR, Jones JF, et al: Stress-related activation of Epstein-Barr Virus. Brain, Behavior and Immunity. 1991, 5:219232.

(14) Glaser R, Pearson GR, Bonneau RH, et al: Stress and the memory T-cell response to the Epstein-Barr Virus in healthy medical students. Health Psychology. 1993, 12:435-442.

(15) Kiecolt-Glaser JK, Glaser R, Dyer C, et al: Chronic stress and immunity in family caregivers for Alzheimer's disease victims. Psychosomatic Medicine. 1987, 49:523-535.

(16) Whitley RJ: Herpes simplex virus infections. In Glaser R, Jones JF (eds), Herpesvirus Infections. New York: Marcel Dekker, Inc., 1994, $1-57$.

(17) Nahmias AJ, Roizman B: Infection with herpes-simplex virus 1 and 2. New England Journal of Medicine. 1973, 7:667-674.

(18) Friedman E, Katcher AH, Brightman VI: Incidence of recurrent herpes labialis and upper respiratory infection: A prospective study of the influence of biologic, social, and psychologic predictors. Oral Medicine. 1977, 43:873-878.

(19) Goldmeier D, Johnson A: Does psychiatric illness affect the recurrence rate of genital herpes? British Journal of Venereal Disease. $1982,54: 40-43$.

(20) Dura J, Haywood-Niler E, Kiecolt-Glaser JK: Alzheimer's and Parkinson's disease dementia caregivers: A preliminary report. Gerontologist. 1990, 30:332-338.

(21) House JS, Landis KR, Umberson D: Social relationships and health. Science. 1988, 241:540-545.

(22) Kiecolt-Glaser JK, Malarkey W, Cacioppo JT, Glaser R: Stressful personal relationships: Endocrine and immune function. In Glaser R, Kiecolt-Glaser JK (eds), Handbook of Human Stress and Immunity. San Diego, CA: Academic Press, 1994, 321-339.

(23) Cohen S, Kamarck T, Mermelstein R: A global measure of perceived stress. Journal of Health and Social Behavior. 1983, 24:385-396.
(24) Blessed G, Tomlinson BE, Roth M: The association between quantitative measures of dementia and senile change in the gray matter of elderly subjects. British Joumal of Psychiatry. 1968, 114:797-811.

(25) Erkinjuntti T, Hokkanen L, Sulkava R, Palo J: The Blessed Dementia Scale as a screening test for dementia. International Journal of Geriatric Psychiatry. 1988, 3:267-273.

(26) Zarit SH, Orr NK, Zarit JM: The Hidden Victims of Alzheimer's Disease: Families Under Stress. New York: New York University Press, 1985.

(27) Orts K, Sheridan JF, Robinson-Whelen S, et al: The reliability and validity of a structured interview for the assessment of infectious iHness. Journal of Behavioral Medicine. 1995, 18:517-530.

(28) Rose RM, Jenkins CD, Hurst MW: Air Traffic Controller Heaith Change. Washington, DC: Department of Transportation, Federal Aviation Administration, 1979.

(29) Adam R: Herpes simplex virus infections. In Glaser R, GotliebStematsky $\mathrm{T}$ (eds), Human Herpesvirus Infections: Clinical Aspects. New York: Marcel Dekker, Inc., 1982, 1-55.

(30) Rapp F: Herpesviruses. New York: Alan R. Liss, 1984.

(31) Long D, Madara TJ, Ponce de Leon M, et al: Glycoprotein D protects mice against lethal challenge with Herpes Simplex Virus Types 1 and 2. Infection and Immunity. 1984, 37:761-764.

(32) Kasl SV, Evans AS, Niederman JC: Psychosocial risk factors in the development of infectious mononucleosis. Psychosomatic Medicine. $1979,41: 445-466$.

(33) Bonneau RH: Experimental approaches to identify mechanisms of stress-induced modulation of immunity to herpes simplex virus infection. In Glaser R, Kiecolt-Glaser J (eds), Handbook of Human Stress and Immunity. San Diego, CA: Academic Press, 1994, 125-160.

(34) Glaser R, Kutz LA, MacCallum RC, Malarkey WB: Hormonal modulation of Epstein-Barr Virus replication. Neuroendocrinology. 1995, 62:356-361.

(35) Glaser R, Gotlieb-Stematsky T (eds): Human Herpesvirus Infections: Clinical Aspects. New York: Marcel Dekker, Inc., 1982, 169-193.

(36) Glaser R, Jones J (eds): Human Herpesvirus Infections. New York: Dekker, 1994.

(37) Kiecolt-Glaser JK, Marucha PT, Malarkey WB, Mercado AM, Glaser R: Slowing of wound healing by psychological stress. The Lancet. 1995, 346:1194-1196.

(38) Kiecolt-Glaser JK, Glaser R, Gravenstein S, Malarkey WB, Sheridan $\mathrm{J}$ : Chronic stress alters the immune response to influenza virus vaccine in older adults. Proceedings of the National Academy of Sciences. 1996, 93:3043-3047.

(39) Hobson D, Curry RL, Beare AS: Hemagglutination-inhibiting antibody titres as a measure of protection against influenza in man. In Perkins FT, Reganey RH (eds), International Symposium on Influenza Vaccines for Men and Horses. New York: S Karger, 1972, 164-168.

(40) Burns EA, Goodwin JS: Immunology and infectious disease. In Cassel CK, Risenberg DE, Sorensen LB, Waish JR (eds), Geriatric Medicine. New York: Springer-Verlag, 1990, 312-329.

(41) Patriarca PA: A randomized controlled trial of influenza vaccine in the elderly. Joumal of the American Medical Association. 1994, 272:1700-1701.

(42) Light E, Niederhe G, Lebowitz BD (eds): Stress Effects on Family Caregivers of Alzheimer's Patients. New York: Springer, 1994. 